

\title{
Evaluation of maintenance parameters of a wind system of energy production per Monte Carlo simulation
}

\author{
Boubacar Niang, K. Adjallah, P. A. Ndiaye
}

\section{To cite this version:}

Boubacar Niang, K. Adjallah, P. A. Ndiaye. Evaluation of maintenance parameters of a wind system of energy production per Monte Carlo simulation. Journal des Sciences pour l'Ingénieur, 2007, 8, pp.14-19. hal-03045179

\section{HAL Id: hal-03045179 \\ https://hal.univ-lorraine.fr/hal-03045179}

Submitted on 7 Dec 2020

HAL is a multi-disciplinary open access archive for the deposit and dissemination of scientific research documents, whether they are published or not. The documents may come from teaching and research institutions in France or abroad, or from public or private research centers.
L'archive ouverte pluridisciplinaire HAL, est destinée au dépôt et à la diffusion de documents scientifiques de niveau recherche, publiés ou non, émanant des établissements d'enseignement et de recherche français ou étrangers, des laboratoires publics ou privés. 


\title{
Evaluation of maintenance parameters of a wind system of energy production per Monte Carlo simulation
}

\author{
B. Niang ${ }^{1,2}$, K. H. Adjallah ${ }^{1}$, P. A. Ndiaye ${ }^{2}$ \\ ${ }^{1}$ ISTIT, CNRS FRE 2732, Université Technologique de Troie. \\ ${ }^{2}$ Ecole Supérieure Polytechnique, Université Cheikh Anta Diop de Dakar, Sénégal
}

\begin{abstract}
RÉSUMÉ. Une approche du type "open shop » caractérisée par des ressources partagées constituées d'agents mobiles (les algorithmes) avait été précédemment mise en cuvre de notre part pour minimiser le makespan total sur l'ensemble des processeurs de diagnostic d'équipements répartis en vue de répondre aux contraintes de disponibilité maximale du système distribué. Une évaluation est maintenant faite de l'incidence des périodes d'inspections de ces tâches de diagnostic sur les paramètres de maintenance dans le cas d'un système éolien réparable de production d'énergie par simulation Monte Carlo. Les résultats montrent qu'une période d'inspection plus faible et une "fenêtre 》 de remplacement préventif plus large augmentent la disponibilité du système et les coûts de maintenance préventive, mais, d'un autre côté, diminuent les coûts de maintenance corrective, d'où la nécessité d'un compromis.
\end{abstract}

ABSTRACT. An "open shop" approach characterized by shared resources comprising mobile agents (algorithms) was implemented, in a previous paper, to minimize the total makespan on the whole of the distributed equipment diagnostic processors in order to meet the maximum availability constraints of distributed system. An evaluation of the incidence of the inspection periods of these diagnosis tasks on the maintenance parameters in the case of a reparable wind system of energy production by Monte Carlo simulation is made now. The results show that a period of weaker inspection and a "window" of broader preventive replacement increase the availability of the system and the costs of preventive maintenance, but, on the other hand, the costs of corrective maintenance decrease, thus the need for a trade.

MoTS-CLÉS : Diagnostic, ordonnancement, tâche, système distribué, maintenance, disponibilité, Monte Carlo, système éolien. KEYWORDS: Diagnosis, scheduling, task, distributed system, maintenance, availability, Monte Carlo, wind system.

\section{Introduction}

In a recent work, we focussed interest on scheduling of the tasks of periodic diagnosis (to supervise, test and evaluate, identify, detect and interpret the functional state of the equipment) using agents "algorithms" in order to decide the maintenance actions to undertake, to restore the equipments in their proper operating condition. Approached in the form of an "open shop" problem characterized by shared resources of mobile agents (algorithms) through an interconnected network of distributed equipment (figure 1), it was solved by genetic algorithm. We obtained the scheduling of the tasks minimizing the total makespan on the whole of the diagnostic processors of the equipment. We now propose, through a Monte Carlo simulation approach, to evaluate the incidence of the periods of inspections of these diagnosis tasks on the maintenance parameters in the case of a reparable wind system of energy production.

After stating the problem, we make the description of the model used for this simulation and indicate the various assumptions formulated as well as the data of Monte Carlo simulation. The results obtained are analyzed and the conclusion formulated.

\section{Formulation of the problem}

We carry out a study of Monte Carlo simulation on a wind system of energy production to evaluate its measurements of performance for various periods of inspections. Figure 2 presents the principal functional components of the wind system

- The aerodynamic block

- The gearbox

- The electric generator

The wind system with stochastic degradation is supposed to be tested periodically using mobile agents (algorithms) of diagnosis described by Adjallah and al. carrying out a perfect diagnosis so that any degradation is detected [Adjallah 2005] and failing elements repaired or replaced, if necessary, according to the thresholds chosen for the maintenance strategy. The test time is considerable but does not disturb the normal operation of the device and one stick to the times of the results of diagnosis is provided by the agents. The duration of the actions of preventive 
maintenance is negligible while that of repairs (corrective maintenance) is not. After a repair, the system is said to be in a state "as good as new".

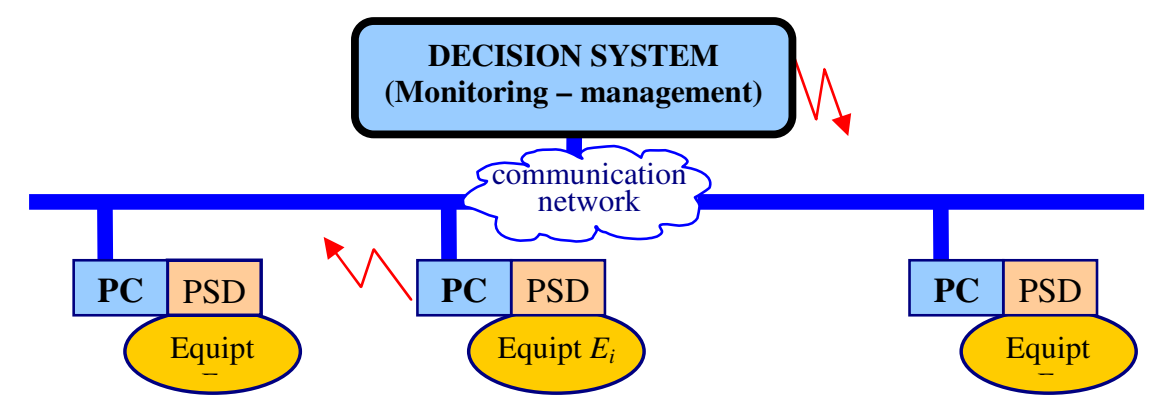

PC: Communication Processor

PSD: Monitoring and Diagnosis Processor

Figure1. Synoptic diagram of a distributed system of diagnosis.

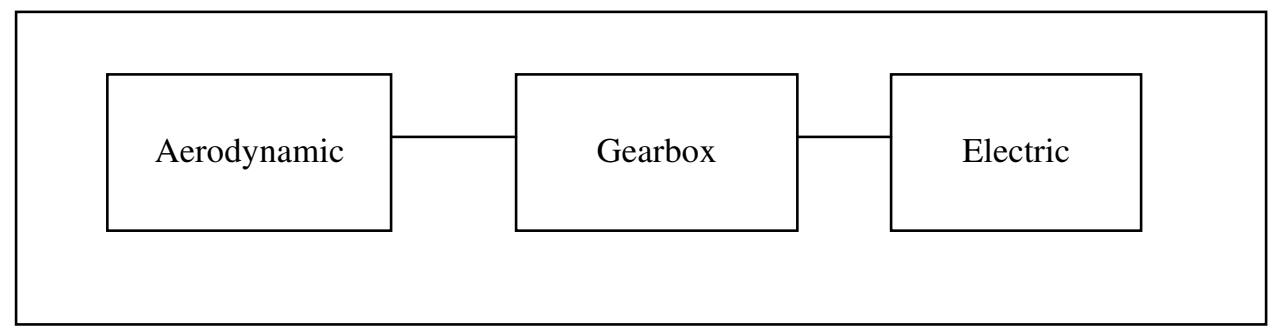

Figure2. Block-diagram of the wind system with the relevant components

Standard "next event" Monte Carlo simulation consists in simulating typical scenarios of life of a system for which the random events (e.g. associated with the failure of the elements) are generated at the software level with the programmed events (e.g. periodic actions of maintenance) and conditional events (e.g. initiated by occurred of other events), while remaining most realistic as possible [Rausand 2004].

\section{Models and Monte Carlo simulation}

\subsection{Model of the system}

We consider a serial structure system of study made up of three relevant components: aerodynamic block, the gearbox and the electric generator, subject of periodic software inspections.

In the case of the study of the reliability of maintained systems, it is essential to specify the policy of the implemented preventive maintenance. One distinguishes, in addition to the policies of replacement based on "the age" and of systematic replacement, that known as condition-based maintenance $(\mathrm{CBM})$ : it is a policy in which the action of maintenance is decided on the basis of the measurement of one or several variables correlated with a degradation or a loss of system performance. The type of maintenance action and the date are decided on the basis of analysis of the values of measurements and a decision is made when a variable exceeds a preset threshold. The state space of the system can thus be divided into various zones of decisions such that each one corresponds to a decision of a specific maintenance.

We consider a policy of condition-based maintenance with preventive replacements on a process model of stochastic deterioration in figures 3 and 4.

Each component of the system (serial structure) has a degradation process as represented in figures 3 and 4 . The deviance compared to its normal state is described by a random variable $\mathrm{Xd}(\mathrm{t})$ with the following assumptions:

- At the initial time $\mathrm{t}=0$ and after each replacement $\mathrm{Xd}(\mathrm{t})=0$, the component is known as in a "state as new".

- The increments in an interval of time are nonnegative, stationary and statistically independent. 
- When the process of degradation $\mathrm{Xd}(\mathrm{t})$ of a component exceeds a level of failure $\mathrm{LX}_{\mathrm{P}}$, a breakdown of the system occurs, it is known as a faulty state.

- The process of degradation is observed with intervals of regular time $\mathrm{t}_{\mathrm{k}}=\mathrm{K} . \Delta \mathrm{T}$, where the unit step of time $\Delta \mathrm{T}$ is a parameter of our simulation ( $\mathrm{T}$-inspec).

- The maintenance decision at time $t_{k}$ is made on the basis of cumulated variation of degradation at time $t$.

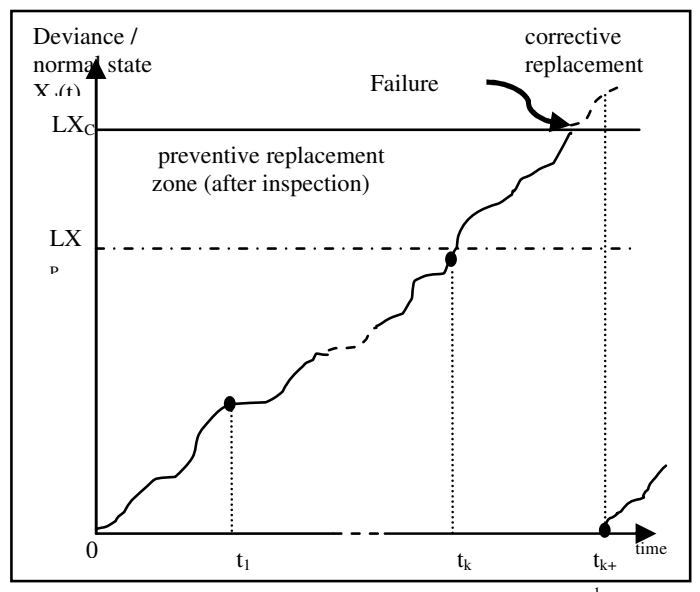

Figure3: Stochastic degradation model of component (Correc. Maint)

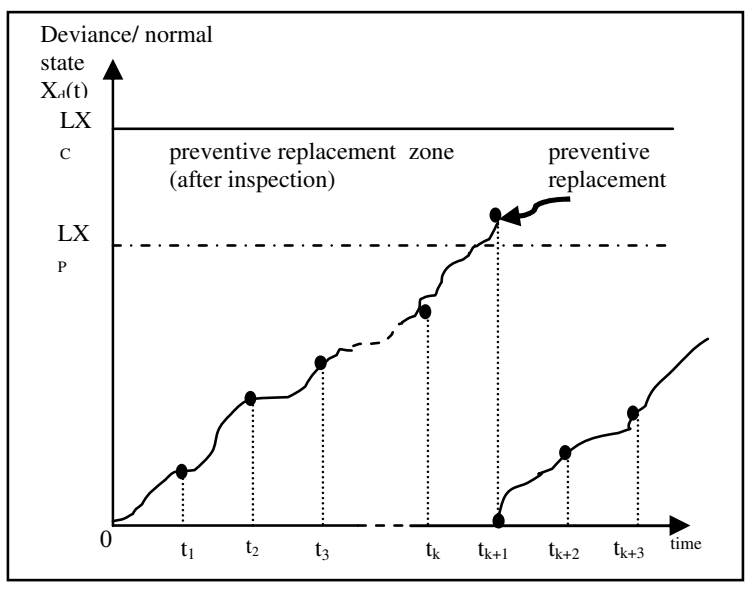

Figure4: Stochastic degradation model of component (Prev.. Maint)

\subsection{System simulation}

The method of event graph proposed by Schruben [Schruben 1983] then Som and Sargent [Som 1989] is used to model the simulation in the form of events and variables on figure 5.
The system with three serial elements (components) has a mode of complete and permanent gradual failure according to the classification of Blanche and Shrivastava [Blanche 1994], and has a resource of repair.

Assumptions of simulation:

- Degradations (deviance compared to the preceding state) of each component arrive according to an exponential distribution of parameter (representing the 'MTBD' average time between degradations) $\alpha_{d i}=\frac{1}{\lambda_{d i}} \quad$ (with $\lambda_{d}$ the rate of degradation of component $i$ )

- When the cumulated deviance of a component exceeds the threshold of preventive maintenance but is below the threshold of failure and that an inspection occurs then the action of preventive maintenance is carried out and the component sets out again in a "state as good as new" (its slack variable of degradation is re-initialized to zero, see figure 4).

- Repairs also take place according to an exponential distribution of parameter $\alpha_{R i}$ (representing the 'MTTR' $\approx$ 'MDT')

- If the cumulated deviance of a component reaches the threshold of failure then the system does not function more, one repair is started at the end of which the system is restarted, the component "as good as new" (see figure 3).

- One does not consider an interaction between the failures of the components although, in practice, that is very probable.

- The duration of the action of preventive maintenance is supposed to be negligible contrary to that of corrective maintenance.

- Simulation is finished (for each period of selected inspection) at the end of a specified time of mission and the parameters of maintenance which are calculated. Simulation is reproduced several times with different seed to deduce the estimate average parameters.

\section{Results and analysis}

In the Hua thesis about the optimization of the reliability of wind electric generators, the maintenance and reliability data are provided for various categories of wind turbines. Those were used as reference for the choice of the values of the 'MTBD' (average time between degradations) of the components. 
The models are implemented with algorithms programmed in $\mathrm{C}$ language.

The results of Monte Carlo simulation, in the form of estimated averages of the parameters over ten years operating life of various values of inspection periods (T-inspec) make it possible to establish the graphs below.

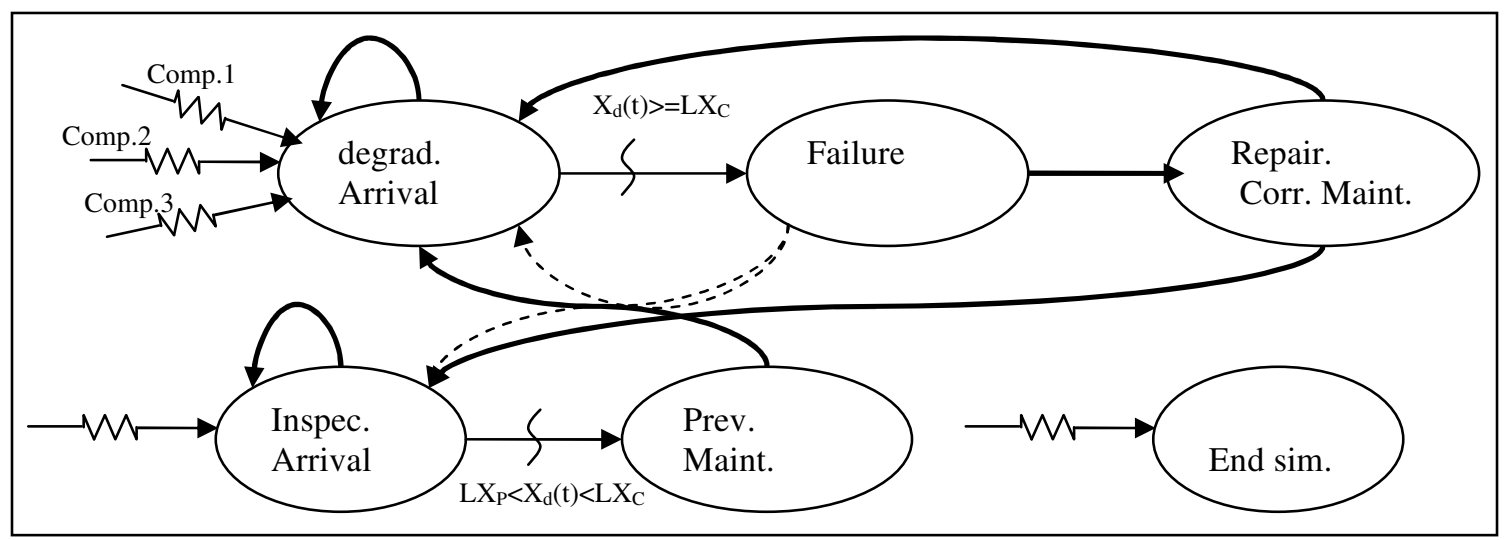

Figure5: Model of graph events simulation

Table 1: Data of the wind turbine

\begin{tabular}{|c|c|c|c|}
\hline 5MW Wind turbine & $\begin{array}{c}\text { Degradation Rate }\left(\lambda_{\mathrm{di}}\right) \\
\left(10^{-4} \mathrm{~h}^{-1}\right)\end{array}$ & $\begin{array}{c}\text { 'MTBD' } \\
\text { degradation }(\mathrm{h})\end{array}$ & Repair time $(\mathrm{h})$ \\
\hline Component1 & 1.66 & 6000 & 45 \\
\hline Component2 & 3.33 & 3000 & 45 \\
\hline Component3 & 5 & 2000 & 40 \\
\hline
\end{tabular}

Figure 6-a shows the curves of availability of the system for various limiting threshold values from implementation of action of preventive maintenance. For weak periods of inspection the average availability of the system is higher as the "window" of preventive replacement is larger. It tends all towards the same limit for all the curves for very great periods of inspection as the theoretical analysis proves it.

Indeed, for a device of the alternating renewable process where the stop and operating time are in each case independent and exponentially distributed events with repair and failure rate $\lambda$ and $\mu$ respectively, one establishes that the expression of the availability is

$$
A(t)=\frac{\mu}{\lambda+\mu}+\frac{\lambda}{\lambda+\mu} e^{-(\lambda+\mu) t}
$$$$
A=\lim _{t \rightarrow \infty} A(t)=\frac{\mu}{\lambda+\mu}=\frac{1 / \lambda}{1 / \lambda+1 / \mu}=\frac{M T T F}{M T T F+M D T}
$$

In figure 6-b, one observes the very significant impact of the "window" of preventive replacement on the average number of failures of the system. For weak periods of inspection $(<100 \mathrm{~h})$ the number of failures grows significantly as this "window" is reduced. On the other hand for very large periods of inspection ( $>5000 \mathrm{~h})$, for any size of the "window", one tends towards a higher same number of failures.

Figure 7-b confirms, as could be expected, hat a "window" of broader preventive replacement significantly increases the number of preventive maintenance actions for weak periods of inspection $(<100 \mathrm{~h})$. Then it is noted that for larger periods of inspection, one tightens towards zero action of preventive replacement. The lower number of degradations for a small "window", on figure 7-a, is explained by the fact that it induces a higher number of failures during which every degradation arrival is suspended including on the non-defective components of the system (complete system stopped. 


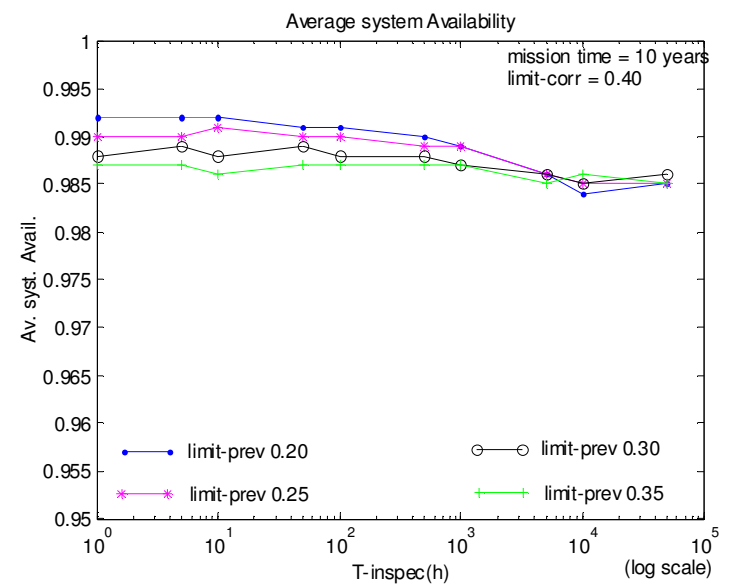

(a)



(b)

Figure6: Availability (a) and number of failures (b).

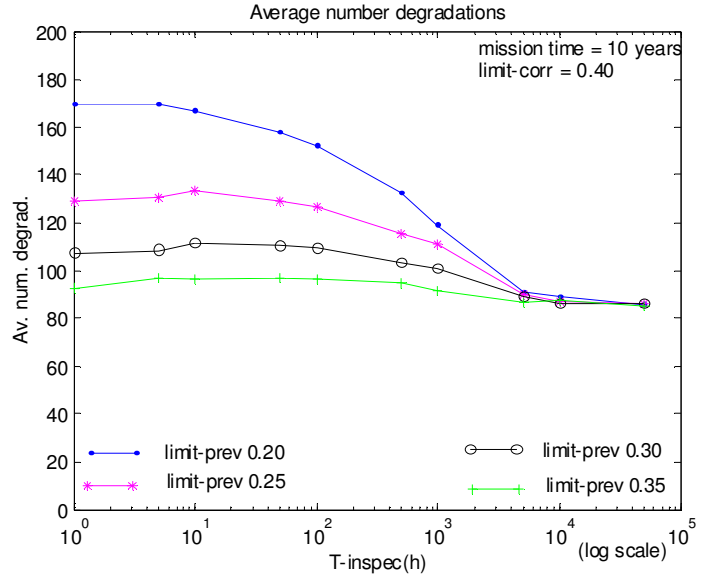

(a)



(b)

Figure7: Number of degradations (a) and preventive maintenance (b).

The results obtained in this Monte Carlo simulation for the evaluation of the parameters of maintenance of a wind system of energy production shows that the minimization of the period of inspection increases the availability of the system. However this availability depends on the "window" of preventive replacement: it increases when this "window" becomes broader. In addition, the number of actions of preventive maintenance to undertake also increases. A tradeoff is then to find between the desired availability and window cuts, especially when the cost and the duration of the actions of preventive maintenance are significant. These results can thus be useful within the framework of scheduling of diagnosis tasks using mobile algorithms (agents) on a distributed system, to determine the maximum limit of inspection period where the availability is optimal.

\section{Conclusion}

One can assimilate the combined execution of algorithms of diagnosis of a machine with a periodic "software inspection". In this work, using a simulation Monte Carlo, we show the latter's impact on the optimization of the maintenance resources and the increase in the availability of the systems by the adequate choice of the limiting degradation thresholds of the maintenance policies (preventive, corrective). 


\section{References}

[1] Adjallah, K.,H., Niang, B., et Ndiaye, P., A., Modèle de gestion de tâches de diagnostic à distance à base d'un système distribué, 2ème Colloque Int. Francophone PENTOM'2005 (Performance et Nouvelles Technologies en Maintenance), Marrakech, 2005.

[2] Blanche, K.M., and Shrivastava, A.B., Defining failure of manufacturing machinery and equipment. In Proceedings from the annual reliability and maintainability symposium, 1994.

[3] Christer, A., Wang, W., Sharp, J., A state space condition monitoring model for furnace erosion prediction and replacement. Eur. J. Oper. Res. 101, 1997

[4] Grall, A., et al., A condition-based maintenance policy for stochastically deteriorating systems, Reliability engineering and system safety (76), 2002.

[5] Hua, Chen, Generating system reliability optimization, Ph.D. thesis, University of Saskatchewan (Canada), 2000
[6] Kelton, W. D., Law, A., Simulation Modeling and Analysis, 3th Edition, McGraw-hill, 2000.

[7] Rausand, M., Hoyland A., System Reliability Theory, models, statistical methods and applications, 2nd Edition, John Wiley \& Sons, 2004.

[8] Schruben, L.W., Simulation modelling with event graphs, Commun. Assoc. Comput. Mach. 26, 1983.

[9] Schruben, L.W., Mathematical programming models of discrete event system dynamics, Proceedings of the 2000 Winter simulation conference, 2000.

[10] Som, T.K., and Sargent, R.G., A formal development of event graphs as an aid to structured and efficient simulation programs, ORSA J. Comput. 1,1989

[11] Wang, W., Christer, A., Towards a general condition based maintenance model for a stochastic dynamic system. J. Oper. Res. Soc. 51, 2000. 